\title{
PANORAMA DA PÓS-GRADUAÇÃO EM EXTENSÃO RURAL: DESAFIOS E PERSPECTIVAS CONTEMPORÂNEAS
}

\section{LANDSCAPE OF GRADUATE GRADUATION IN RURAL EXTENSION: CHALLENGES AND PERSPECTIVES}

\author{
Parley Lopes Bernini Silva ${ }^{1}$ \\ Érica Arruda Peluzio ${ }^{2}$ \\ Sheila Maria Doula ${ }^{3}$
}

\begin{abstract}
Resumo
O artigo teve como proposta central o mapeamento histórico do Programa de Pós-Graduação em Extensão Rural, vinculado ao Centro de Ciências Agrárias da Universidade Federal de Viçosa entre os anos de 1968 a 2018, correlacionando o quantitativo de graduados pertencentes das múltiplas áreas do saber na qualidade de ingressantes em seu corpo discente, o qual fundamenta-se e dá ênfase na interdisciplinaridade. A pesquisa teve seu aporte ancorado no levantamento bibliográfico e documental junto a Secretaria de Pósgraduação do programa aliado a análise de conteúdo favorecendo, assim, sua execução. Analisaram-se 641 matriculados objetivando entender quão se deu a presença de profissionais das diversas áreas do saber no programa Strictu Sensu, bem como tal fenômeno correlaciona com a prática da Extensão Rural, pertencente no campo das Ciências Agrárias I, a qual utiliza teórica e metodologicamente das Ciências Humanas e Sociais Aplicadas na temática de Agrárias. Conclui-se que a polissemia de pesquisadores egressos demonstra a orientação do programa de pós-graduação às questões multidisciplinares que interseccionam na temática rural, enfaticamente necessárias na atualidade para a formação de Mestres e Doutores em Extensão Rural, priorizando análises locais relativas ao cidadão rural reveladas em suas duas linhas de pesquisa que corroboram na sua existência por mais de meio século.
\end{abstract}

Palavras-chave: ciências agrárias I; Alumnus; Análise Temporal.

\footnotetext{
* Artigo Original: Recebido em 04/10/2021 - Aprovado em 05/11/2021.

${ }^{1}$ Gestor de Turismo, Mestre em Extensão Rural, Pesquisador no Grupo de Pesquisas Observatório da Juventude Rural, Viçosa/ MG, Brasil. e-mail: parley.silva@ufv.br ORCID: http://orcid.org/0000-0001-9278-1235 (autor correspondente)

${ }^{2}$ Psicóloga, Mestra em Extensão Rural, Professora no Centro de Ciências Humanas, Centro Universitário de Viçosa (FACISA -UNIVIÇOSA), Viçosa/MG, Brasil. e-mail: erica.peluzio@ufv.br ORCID: http://orcid.org/0000-0003-3948-9563

${ }^{3}$ Pós-Doutorado do Programa Postdoctoral de Investigación en Ciencias Sociales, Niñez y Juventud da CLACSO, Professora Associada do Departamento em Economia Rural, Universidade Federal de Viçosa (UFV), Viçosa/MG, Brasil. e-mail: sheiladoula@gmail.com ORCID: http://orcid.org/0000-0003-0310-9055
}

* Apoio financeiro: O presente trabalho foi realizado com apoio da Coordenação de Aperfeiçoamento de Pessoal de Nível Superior - Brasil (CAPES) - Código de Financiamento 001 


\section{Abstract}

The main proposal of the article was the historical mapping of the Postgraduate Program in Rural Extension, linked to the Center for Agricultural Sciences of the Federal University of Viçosa between 1968 and 2018, correlating the number of graduates belonging to multiple areas of knowledge in quality of freshmen in its student body, which is based on and emphasizes interdisciplinary. The research had its contribution anchored in the bibliographic and documental survey with the Post-Graduate Department of the program, allied to content analysis, thus favoring its execution. 641 registered students were analyzed in order to understand the presence of professionals from different areas of knowledge in the Strictu Sensu program, as well, as how this phenomenon correlates with the practice of Rural Extension, belonging to the field of Agricultural Sciences I, which uses theoretically and methodologically of Human and Social Sciences Applied to Agrarian Theme. Concludes that the polysemy of graduate researchers demonstrates the orientation of the graduate program to multidisciplinary issues that intersect in rural issues, emphatically necessary today for the training of Masters and Doctors in Rural Extension, prioritizing relative local analysis to the rural citizen revealed in his two lines of research that corroborate his existence for more than half a century.

Keywords: agrarian science I; Alumnus; Temporal Analysis.

\section{Introdução}

Este estudo tem por alicerce o conhecimento do ser humano, com recorte nas suas vivências alcançadas advindas de sua relação com o ambiente em que vive e, individualmente, com os que busca conhecer. Assim, Soares (2009), comenta que todo saber revela-se por intervém das experiências adquiridas; da interação com o inaudito; da diversidade e do que é desconhecido, gerando o desenvolvimento do ser humano e seu amadurecimento pessoal; social; científico e profissional.

Igualmente, ao estudar a prática de Extensão Rural (ER) e seus objetos de saber não se faz distinção ao dito ora que atém como característica principal sua multiplicidade de estudos definidos nos palcos políticos; econômicos; sociais; culturais e ambientais, exigindo sua intersecção a sociedade que integra (DIAS, 2018). Entende-se, pois, a Extensão Rural enquanto área aplicada tendo seus saberes adquiridos através das demais Ciências que corroboram em sua interdisciplinaridade frente às questões que afetam, enfaticamente, o cidadão rural.

Dado o exposto, a análise aportou em exibir e, $a$ posteriori, debater o quantitativo de profissionais pertencentes às diversas áreas do saber ingressantes no Programa de Pós-graduação em Extensão Rural da Universidade Federal de Viçosa (PPGER-UFV), bem como o programa se situa com linhas de pesquisa que corroborem nas premissas de que a ER assume multidisciplinaridade em tempos atuais, em conformidade com o documento de Área Ciências Agrárias I, disposto pela CAPES (2019).

O trabalho tem sua execução justificada ao considerar que a prática de ER "fundamenta teórica e metodologicamente em diversas subáreas das chamadas ciências sociais aplicadas e das ciências humanas, e aplica estes conhecimentos, no âmbito das ciências agrárias" (DOULA; SOUZA, 2006, p. 282), priorizando "estudos sobre quem é, o que pensa e como vive o homem do meio rural" (UFV-CCA, 200-, p. 11). É no debate de expor a necessidade de graduados nas diversas áreas do conhecimento capazes de atender estas lacunas e sua busca em romper a fronteira de pensamento de uma ciência particularizada que o artigo situa, tendo como objeto empírico o PPGER-UFV.

Nisto, na seção "O estudo das Ciências Agrárias no Brasil: questões de fundo" se faz presente um levantamento histórico do tema e seu pioneirismo no Brasil que, dentre outros, oportunizou a prática de ER nacionalmente. Já a subseção "As ações pioneiras de extensão no país: sob um olhar histórico $e$ constante" traz para o debate a inserção da ER no país, como suas atividades impactaram aqueles que vivem no campo e os resultados que obteve e obtém em tempos atuais, complementado com "O lócus da pesquisa: Programa de Pós-Graduação Strictu Sensu em Extensão Rural da UFV" onde se discute 
suas linhas de pesquisa e o delineamento frente à multidisciplinaridade exigida para área, tornando-o, de tal modo, um dos programas de pós-graduação mais antigos do país.

Não menos importante, em "Resultados e Discussões" desenha-se um panorama do que foi apresentado ao longo do artigo; os campos de avanços e dificuldades da ER, bem como as contribuições e limitações que esta pesquisa apresenta às vistas do PPGER-UFV. O trabalho, por sua vez, encerrase com as considerações finais referências que sustentaram sua realização.

\section{Metodologia}

Metodologicamente delimitado pela revisão bibliográfica e documental, o artigo propõe situar a problemática num panorama teórico-conceitual das categorias analíticas Ciências Agrárias e Extensão Rural, intimamente veiculadas ao corpus empírico deste ensaio. O levantamento de livros; artigos; leis; normativas e demais produções científicas que abordassem tais conceitos tiveram destaque haja vista que, neste método, sua execução advém de referenciais teóricos publicitados e problematizados anteriormente por outros pesquisadores, tendo, por fim, embasamento teórico suficientemente capaz de reunir a temática que se propõe analisar (RAUPP; BEUREN, 2006).

A coleta do material, por sua vez, teve aporte no método de Pesquisa Documental junto à Secretaria do PPGER em 2019-2020. Raupp e Beuren (2006), apostilam que esta intervenção se baseia em materiais que pouco ou nada foram estudados estando desprovidos de tratamento analítico denso e consolidado. Assim, nesta abordagem, o pesquisador tem o documento enquanto objeto de pesquisa, com todas oportunidades e dificuldades que lhe convém (SÁSILVA; ALMEIDA; GUINDANI, 2009) SÃO TRÊS AUTORES, INCLUSOS NAS REFERÊNCIAS. A tabulação dos dados, feita em ano subsequente, apropriou-se da técnica de análise de conteúdo.
Bardin (1977), esclarece que a análise de conteúdo estrutura-se em quatro etapas, sendo-as: 1) Organização - ajuizamento do material que será utilizado (artigos, repositórios, sites institucionais e afins); 2) Codificação - faz-se uma unidade de registro da análise (a prática de ER frente a interdisciplinaridade que o campo das Ciências Agrárias I exige); 3) Categorização - atrelamento dos elementos realizados em razão dos caracteres comuns (aqui utilizado o agrupamento temático sob a forma gráfica); e 4) Inferência - análise e considerações dos dados frente a bibliografia utilizada assinalando as contribuições e limitações.

\section{Referencial teórico}

3.1 O estudo das Ciências Agrarias no Brasil: questões de fundo

A consolidação das Ciências Agrárias (CA) no país é consideravelmente recente em decorrência da sua independência nacional e, consequentemente, soberania. Desde o período de colonização até o final do século XVIII não se estabelecia como preocupação o desenvolvimento tecnológico, mas sim o modelo de extrativismo e escravidão ordenados pela coroa portuguesa. O que se tinha, ainda a passos curtos, era as nomeadas Ciências Naturais pautadas numa observação rasa e analiticamente mal definida (CAPES, 2019).

As melhorias aconteceram tão-só “com a chegada da corte portuguesa no Brasil, Dom João VI buscou melhorar as condições da colônia" (CAPES, 2019, p. 2), que propusera desenvolver as CA no país e suas ramificações, dentre elas a Agronomia, onde a Extensão rural veicula-se. Com a memória de uma economia colonial majoritariamente estabelecida na exploração (como o do ouro e látex), via-se a necessidade de interiorizar suas buscas que, a posteriori, calcavam sua economia em bens agropecuários (como fumo, algodão e cana-deaçúcar). Mais ainda:

Os avanços científicos e tecnológicos a partir das décadas de 1940 e 1950 viabilizaram tecnologias como a fixação biológica do nitrogênio desenvolvidas no estado de São Paulo e Rio Grande do Sul, respectivamente, e na década de 60 , com a ocupação 
agrícola de mais de dez milhões de hectares de Cerrado. Até a década de 1990, grande parte do conhecimento gerado na área das Ciências Agrárias pelos Programas de Pós-graduação. (CAPES, 2019, p. 3).

Já em 1973, sob operação da Empresa Brasileira de Pesquisa Agropecuária (Embrapa), cabia a instituição produzir pesquisas que complementassem as que se tinham nas universidades, gerando os saberes que teriam aplicabilidade às questões do rural e quem nele integra. A organização alçou de "repassadora de tecnologias modernas" (SALLES-FILHO, 2000 apud CAPES, 2019, p. 3), dependente de tecnologias externas e de padrões que não representavam a realidade local a um "científico/informacional" (CAPES, 2019, p. 3) onde pretendia-se sua independência científica e pela "formação exclusiva de recursos humanos altamente qualificados" (CAPES, 2019, p. 3) oriundos dos programas de pósgraduação na área de CA.

A pós-graduação de Ciências Agrárias no país têm sua origem na Universidade Federal de Viçosa (à época nomeada Escola Superior de Agricultura e Veterinária), através do Mestrado em Fitotecnia que expunha, pioneiramente, os moldes do que seria a pós-graduação Strictu Sensu no país. O programa inicia-se em "1965 a partir do Parecer 977 do Conselho Nacional de Educação. Este parecer autorizou, inicialmente, o funcionamento de dois cursos de mestrado em Agronomia na ESALQ e na UFRGS" (CAPES, 2019, p. 3). Estes, pautavam numa formação humana e de saberes altamente qualificados defendidos pela extinção das cátedras em 1968 exigindo a preocupação com o rigor científico aplicado as questões locais. Nisto:

A história da UFV começou a ser contada em 1926, com a criação da Escola Superior de Agricultura e Veterinária (ESAV), na cidade de Viçosa, Zona da Mata de Minas Gerais. Inspirada nos land grant colleges (escolas superiores agrícolas norte-americanas criadas no século
XIX), ela privilegiava, na formação de seus alunos, não só a teoria, mas particularmente a contextualização dessa teoria na realidade regional. Além de participarem de aulas práticas na ESAV, os estudantes também visitavam as propriedades rurais da região, buscando ampliar seus conhecimentos. (UFV-CCA, 200-, p. 4).

No decorrer de seis décadas desde sua aplicabilidade no país, a área se exibe consolidada e com números que expressam sua competência nacional. Titularam-se nos últimos 20 anos “40.093 Mestres acadêmicos, 17.482 Doutores acadêmicos e 1.335 Mestres profissionais" (CAPES, 2019, p. 4), o que por si só já orienta seu impacto na sociedade brasileira. A contribuição científica da CA e sua relevância é, mais ainda, evidenciado ao ler que:

[...], a área de Ciências Agrárias é responsável pela segunda maior produção de documentos científicos no país [...]. A contribuição da área para a produção de conhecimento fez com que o país saísse, em menos de 15 anos, do $21^{\circ}$ para o $14^{\circ}$ lugar em 2017 na produção mundial de documentos científicos (Base Scimago). O Brasil também apresenta a maior produção desses documentos na América Latina. Em 2018 ocupou a $3^{\mathrm{a}}$ posição neste quesito em relação à produção intelectual mundial na área de Agrárias, somente atrás dos Estados Unidos e da China. (CAPES, 2019, p. 4).

Tais resultados emergiram de diversos convênios internacionais; pela revisão dos modelos científicos norte-estadunidenses adotados na CA do país; pela formação de recursos humanos que entendam sua realidade local e especialmente pela definição de professor-pesquisador titular de competência acadêmica de lócus empírico às questões locais, oportunizando a titulação de Mestres e Doutores na área cientes da realidade social que vivem. 
Por fim entende-se que em tempos atuais o campo das Ciências Agrárias “também deverá intensificar a qualidade em detrimento da quantidade, devendo ainda ser útil, dirigida e aplicada, e também inclusiva para todos os atores da sociedade" (CAPES, 2019, p. 6). Objetivando a análise das peculiaridades deste campo que a Ciências Agrárias I tem destaque, visto que intersecciona teórico e metodologicamente no campo das Ciências Humanas e Ciências Sociais Aplicadas, analisando aspectos sociais a quem viva no campo. Conforme orientação da Coordenação de Aperfeiçoamento de Pessoal de Nível Superior (CAPES, 2021):
A classificação das Áreas do Conhecimento tem finalidade eminentemente prática, objetivando proporcionar às Instituições de ensino, pesquisa e inovação uma maneira ágil e funcional de sistematizar e prestar informações concernentes a projetos de pesquisa e recursos humanos aos órgãos gestores da área de ciência e tecnologia. A organização das Áreas do Conhecimento na tabela apresenta uma hierarquização em quatro níveis, do mais geral ao mais específico, abrangendo nove grandes áreas nas quais se distribuem as 49 áreas de avaliação da CAPES. Estas áreas de avaliação, por sua vez, agrupam áreas básicas (ou áreas do conhecimento), subdivididas em subáreas e especialidades. (CAPES, 2021).

A Ciências Agrárias I, por sua vez, detém dez subáreas do conhecimento, a saber: Agroecologia, Ciência do Solo, Ciências Florestais, Engenharia Agrícola, Experimentação Agrícola, Extensão Rural, Melhoramento e Recursos Genéticos, Proteção de Plantas, Fitotecnia e Microbiologia Agrícola (CAPES, 2019), tendo pesquisas desde "o melhoramento genético de plantas e animais a estudos importantes sobre quem é, o que pensa e como vive o homem do meio rural" (UFV-CCA, 200-, p. 11) sendo, por fim, a "segmentação da área do conhecimento (ou área básica) estabelecida em função do objeto de estudo e de procedimentos metodológicos reconhecidos e amplamente utilizados" (CAPES, 2021).

Existe, pois, nesta subárea a necessidade de atender o que é técnico, mas também questões relativas as identidades, preferências, representações e posições possibilitando, assim, a qualificação "de profissionais que atuam na assistência técnica rural do país. De modo geral, esses profissionais buscam caminhos mais sustentáveis, que levam à manutenção ou à recuperação das boas condições do meio ambiente e da dignidade do homem do campo" (UFV-CCA, $200-$, p. 11). Sua multidisciplinaridade se justifica ao observar a interface com as diversas áreas do conhecimento que refletem, especialmente, na construção de projetos de pesquisas, dissertações e teses com "um forte componente interdisciplinar, não somente com as áreas do conhecimento que pertencem à grande área de Agrárias, mas também as demais áreas e grande áreas do conhecimento" (CAPES, 2019, p. 9).

É a interdisciplinaridade que norteia o campo das Ciências Agrárias I onde, nele, reside a ER, objeto desta análise. Neste bojo a Extensão Rural, por sua vez, utiliza-se de "técnicas e métodos das áreas de Ciências Humanas Sociais Aplicadas (educação, sociologia, gestão), geografia humana e física, biologia, engenharia, estatística, história e informática" (CAPES, 2019, p. 10), assumindo a utilização de técnicas; métodos; procedimentos e profissionais das mais diferentes áreas do saber em decorrência dos diversos temas que contempla sua análise. Campo este que a própria Extensão Rural em dias atuais preocupa contemplar.

3.2 As ações pioneiras de extensão no país: sob um olhar histórico e constante

As análises atuais da agricultura familiar e das mudanças sociais geradas por ela tornaram palco de amplo debate no cenário acadêmico, onde diferese do capitalismo ao optar pela produção natural (GOODMAN; SORJ; WILKINSON, 2008) e, em contramão, o saber necessário para fazê-la repousa 
na vida rotineira e de processos lógicos carentes de controle - tal qual numa fábrica ou laboratório - (COELHO, 2014). Diante desta pressuposição de dinamicidade, as ações extensionistas tiveram considerável relevância na modernidade do rural, perpassando do saber técnico ao humano.

Após o explicitado e todo impacto da ER aliada à modernidade, a literatura versa que às ações iniciais da extensão tiveram berço estadunidense, logo após a Guerra Civil Americana exibindo "a passagem da estrutura escravista à estrutura mercantil e capitalista" (FONSECA, 1985, p. 37). A forma de produção da agricultura norte-americana alçou cenário global de maneira a gerar uma tendência de como produzir os alimentos nas diversas esferas do globo. Tal fato oportunizou que começasse "atuar empresas capitalistas gigantescas e sua especulação" (ROSA DE LUXEMBURGO, 1976, p. 361 apud FONSECA, 1985, p. 38), iniciando assim aquilo que se nomearia por Extensão Agrícola (mais a frente nomeada Extensão Rural). Este ocorrido provocou dificuldades de adaptação pelos pequenos fazendeiros norte-americanos, não sustentando à concorrência massiva que se estabelecia frente as monoculturas de milho e soja.

Em 1870, frente às questões sociais de como apoiar os produtores familiares, emergia no país os Centros de Agricultura com conferências públicas e cursos ligados à Universidade buscando práticas educativas e, em 1914, ocorre a oficialização do Trabalho Cooperativo de Extensão Rural (FONSECA, 1985). A extensão estadunidense assume então papel de elo entre as estações de pesquisa (geralmente unidas às Universidades) e as populações rurais, que, essencialmente, resumia o conceito "de que era necessário informar e persuadir os agricultores a adotarem melhores práticas agrícolas" (FONSECA, 1985, p. 41). Já na América Latina, as ações de extensão foram propostas por governos locais devidamente conveniadas com às agências americanas de Extensão Rural, genitoras da ideia de que "os que sabem o que é melhor para os agricultores são os cientistas" (BORDENAVE, 1972, p. 3 apud FONSECA, 1985, p. 41).

Este tipo de padrão, intitulado como modelo clássico, serviu de sustento à concepção e arranjo dos Serviços de Extensão inseridos nas regiões tidas por subdesenvolvidas no período pós Segunda Guerra Mundial devido a precarização destes países e a necessidade de fortalecimento da agricultura e boas práticas de plantio/ saúde familiar no campo. Finalmente, a ER era vista como instrumento de melhoria social e de manejo ao cidadão rural (FONSECA, 1985, DIAS, 2018) a regiões pouco desenvolvidas academicamente e profissionalmente, como o caso do Brasil, pouco consolidado politicamente e economicamente.

Categoricamente, pode-se traçar uma linha cronológica da Extensão Rural no Estado brasileiro (Quadro 1). 
Quadro 1 - Ações de extensão rural no Brasil: 1929-2013

\begin{tabular}{|c|c|}
\hline Ano & Descrição \\
\hline $1929-1930$ & $\begin{array}{l}1^{a} \text { ação de extensão rural no país, sendo a } 1^{\text {a }} \text { Semana do Fazendeiro na Escola Superior de } \\
\text { Agricultura e Veterinária - ESAV - (atual UFV) em Viçosa - MG (mantida até hoje). }\end{array}$ \\
\hline 1945 & $\begin{array}{c}\text { Final da } 2^{\mathrm{a}} \text { Guerra Mundial, novo ordenamento geopolítico no globo (capitalismo versus } \\
\text { comunismo). }\end{array}$ \\
\hline 1948 & $\begin{array}{c}\text { Criação da Associação de Crédito e Assistência Rural (ACAR) em Minas Gerais, tendo por } \\
\text { fundador Nelson Aldrich Rockefeller. }\end{array}$ \\
\hline 1956 & $\begin{array}{l}\text { Funda-se a Associação Brasileira de Crédito e Assistência Rural (ABCAR) por Juscelino } \\
\text { Kubitschek. }\end{array}$ \\
\hline 1964 & $\begin{array}{l}\text { Necessidade de reforma agrária; ampliação da agricultura; crise política; migração campo- } \\
\text { cidade e golpe de estado no Brasil. }\end{array}$ \\
\hline 1968 & Início do Mestrado Strictu Sensu de Extensão Rural no país. \\
\hline 1972 & Institui-se a Empresa Brasileira de Pesquisa Agropecuária (EMBRAPA) \\
\hline 1974 & Funda-se a Empresa Brasileira de Assistência Técnica e Extensão Rural (EMBRATER). \\
\hline 1980 & Estagnação econômica, agricultura consolidada, papel da ER cumprido. \\
\hline 1984-1985 & Governo Sarney; período de redemocratização do Estado e lutas por terra. \\
\hline 1990 & Estado mínimo (viés neoliberal), extinção da EMBRATER e crise nos serviços de ER. \\
\hline 1996 & $\begin{array}{l}\text { Cria-se o Programa Nacional de Fortalecimento da Agricultura Familiar (PRONAF); } \\
\text { movimentos sociais pela ocupação de terra. }\end{array}$ \\
\hline 2004 & Reestruturação da Assistência Técnica de Extensão Rural (ATER) pública \\
\hline 2010 & Promulga-se a Lei ATER e aumento de recursos. \\
\hline 2012 & Fóruns de análise da Política Nacional de Assistência Técnica e Extensão Rural (PNATER). \\
\hline 2013 & Funda-se a Agência Nacional Técnica de Extensão Rural (ANATER). \\
\hline
\end{tabular}

FONTE: Elaborado pelos Autores (2020).

É fator relevante compreender como tais ações de ER no país afetaram os estudos do rural em suas diversas áreas (tal qual educativa e social) e como seus serviços pautaram na manutenção destas conquistas. Consequentemente, as ações de extensão não assumem unicamente fatos históricos que se produzem a si mesmos (como tãosó manejo e produção), mas sim nas relações com a sociedade inclusiva (FONSECA, 1985), tendo a abertura as boas práticas de preparo dos alimentos; higiene pessoal e do lar; cuidados ao armazenar os mantimentos e atenção à saúde da família no contexto rural. Questões, estas, reveladas pelos estudos acadêmicos da ER.
A Extensão Rural no Brasil, para além do viés histórico e político, também engloba cursos de pós-graduação strictu sensu com o mesmo nome. Em tempos atuais, existem dois cursos em funcionamento no país: o da Universidade Federal de Viçosa, pioneiro da prática ao ser criado em 1968, e o da Universidade Federal de Santa Maria - UFSM, tendo início em 1975, ambos com a modalidade de Mestrado e Doutorado acadêmico. Como analisam Doula e Souza (2006), esses cursos surgiram no período de mais intensa modernização da agricultura brasileira, chamada de Revolução Verde, sendo inicialmente pautados pela perspectiva difusionista das inovações tecnológicas no espaço rural. 
No entanto, adequando-se às transformações atuais que o rural detém e às novas políticas públicas de extensão rural, a área tem reformulado seu modelo de atuação objetivando capacitar os futuros mestres e doutores para interpretar e agir não só na dimensão técnica, mas "incorporando aos seus conteúdos um conjunto pluralista de abordagens de extensão, que levam em conta o novo contexto agrário, econômico e social sobre o qual atuam ou irão atuar os extensionistas" (DOULA; SOUZA, 2006, p. 285), exigindo modernização constate destes cursos num caráter teórico-empírico.

Tal modernidade, segundo Giddens (1991, p. 45), "consiste no fato de que as práticas sociais são constantemente examinadas e reformuladas à luz de informação renovada sobre essas próprias práticas, alterando assim seu caráter”. Entende-se que a modernidade é constituída por conhecimento o qual é constantemente estudado, tendo por base uma análise reflexiva. A reflexividade moderna é estruturada a medida de que todas as práticas sociais são examinadas, estudadas e reestruturadas sob o prisma de informação renovada oriundas das práticas de cada organização social que modela seu estilo de organização.

Nesse bojo de reanálises e novas problematizações que a ER se insere haja vista analisar as relações sociais, políticas, culturais e econômicas do cidadão rural, para além do que é tão-só técnico que ocorrem, sobretudo, na formação a nível de Mestres e Doutores na área.

\subsection{O lócus da pesquisa: Programa de Pós- Graduação Strictu Sensu em Extensão Rural da $U F V$}

O PPGER vincula-se ao Departamento de Economia Rural (DER) e ao Centro de Ciências Agrárias da Universidade Federal de Viçosa (UFVCCA), oferecendo capacitação profissional a nível Strictu Sensu. O mestrado recebeu aceite pelo Conselho Universitário em novembro de 1967 e deu início às atividades em ano seguinte (mais precisamente em março de 1968), tendo completado 51 anos em março deste ano (PROGRAMA, 2018). Em março de 2011, o programa pleiteou aprovação para o curso de Doutorado e, através da portaria $\mathrm{n}^{\circ}$ 982, de 26 de julho de 2012, teve admissão nesta modalidade (BRASIL, 2012). Há de se observar que (UFV-CCA, 200-):
O Departamento de Economia Rural (DER) é uma das unidades mais antigas da UFV, apresentando uma trajetória que se entrelaça com a própria história da UFV. Criado em 1926, o então Instituto de Economia Rural da ESAV (Escola Superior de Agricultura e Veterinária) receberia o nome de Departamento de Economia Rural em 1931. Desde o início, o grande prestígio desfrutado pelo departamento, particularmente o reconhecimento do governo federal, fez com que obtivesse verbas da Comissão Supervisora dos Planos dos Institutos (COSUPI), bem como o apoio de instituições internacionais, como a Fundação Ford. [...] Em decorrência do prestígio do DER, professores norte-americanos vieram a Viçosa por meio do convênio com a United States Agency for International Development (USAID), para auxiliar a estruturação do Programa de Pós-Graduação do Departamento de Economia Rural. [...] Outro fato marcante aconteceu em 1968, quando o DER atender uma antiga e grande demanda da sociedade: a Pós-Graduação em Extensão Rural. Um dos mais antigos no país, o Mestrado strictu sensu, possibilitou a capacitação de inúmeros extensionistas, possibilitando a reflexão crítica sobre as políticas públicas desenvolvidas para o campo. (UFV-CCA, 200-, p. 41).

Percebe-se, portanto, que o Programa exibe um percurso sólido, ora que até o ano de 2017 foram defendidas 526 dissertações e 12 teses. Amparado ainda neste ano, matricularam-se no PPGER 70 discentes, sendo: 47 a nível de mestrado, 23 a nível de doutorado e um pesquisador em estágio pósdoutoral. Entender tal situação denota a amplitude de sua produção acadêmica na área de Ciências Agrárias I, sobretudo com o aporte de disciplinas como Antropologia; Sociologia; Políticas Públicas e Administração que são ofertadas regularmente ofertadas (PROGRAMA, 2018). 
O PPGER (a nível de Mestrado e Doutorado) conserva como proposta institucional sua entrada no social. Parcerias, convênios, programas e projetos direcionados a elevação do desenvolvimento rural e para a melhoria do modus vivendi das populações no meio rural (sejam elas de comunidades e assentamentos rurais, de reservas extrativistas, de comunidades quilombolas, entre outras) são destaques nas suas produções científicas e técnicas.

Há também em seu histórico uma posição pioneira e de referência nos debates socioeconômicos; antropológicos; agrários; históricos e ambientais no contexto das Ciências Agrárias I. Evidencia-se, assim, considerável importância que o PPGER adota em outras áreas de avaliação da CAPES tal qual a de Ciências Sociais e Humanas (PROGRAMA, 2018), resultando em seu conceito CAPES 4. Desta maneira, vê-se que o Curso alçou no decorrer de cinco décadas de atuação, uma ação pautada por intensa inserção social, desenvolvendo convênios e trabalhos voltados para o desenvolvimento rural a nível nacional e, também, para além de suas fronteiras, alçando a América Latina, África e Europa com estudantes internacionais (PROGRAMA, 2018).

Preocupações com os riscos socioambientais; com as questões propriamente sociais que vêm afetando o campo como os novos atores sociais e processos organizacionais e comunicacionais que se manifestam no mundo rural tornaram-se eixo principal para sua área de concentração e linhas de pesquisa (PROGRAMA, 2018). Abaixo, têm-se o Quadro 2 expondo a área de atuação e linhas de pesquisa vigentes no PPGER:

Quadro 2 - Área de concentração e linhas de pesquisa do PPGER

Área de concentração: Extensão Rural, Instituições e Desenvolvimento Rural

\begin{tabular}{cc}
\hline \multicolumn{2}{c}{ Área de concentração: Extensão Rural, Instituições e Desenvolvimento Rural } \\
\hline $\begin{array}{c}\text { LINHA 1 - Governança de Recursos Comuns, } \\
\text { Sistemas Agroalimentares e Meio Ambiente }\end{array}$ & LINHA 2 - Cultura, Políticas Públicas e \\
Comunicação
\end{tabular}

FONTE: Programa de Pós-Graduação em Extensão Rural (2018).

O programa, lido suas linhas, preconiza uma organização atual e reformulação de sua identidade incorporado as variações socioambientais, fundiárias, políticas e tecnológicas decorrentes do célere processo de modernização e do aumento das atividades agrícolas (ou não) no espaço rural
(PROGRAMA, 2018). Ao mesmo tempo nota-se no PPGER a ênfase nas questões sociais e identitária de quem é esse cidadão rural (PROGRAMA, 2018; UFV-CCA, 200-) enfaticamente na segunda linha. De tal modo, mostra-se aberto ao pluralismo teórico e de formações que a atualidade rural exige. Pode-se 
assim entender que, de acordo com o exposto no site do PPGER:

As linhas de pesquisa do Programa caracterizam-se por: a) referir-se a uma área de trabalho ou campo de conhecimento cujo domínio é perseguido pelo pesquisador; b) referir-se a problematizações que o pesquisador faz sobre a realidade de forma processual; c) vincularse a interesses profissionais e acadêmicos do pesquisador, interesses institucionais e da comunidade científica, bem como a demandas de setores sociais mais amplos; d) envolver uma procura por sistematização de conhecimentos de natureza teórica, metodológica; e etc.) pressupor tanto a aquisição de conhecimentos como sua crítica e disseminação. (PROGRAMA, 2018, n. p.).

\section{Resultados e discussões}

As análises ocorreram em dois eixos norteadores: inicialmente dividiu-se os estudantes através das
Grandes Áreas do Conhecimento do Conselho Nacional Científico e Tecnológico (CNPq), isto em cinco blocos temporais (quatro com 10 anos e um com 11 anos) e finalmente buscou-se correlacionar suas múltiplas formações antecessoras ao ingresso no programa com a hipotética do extensionista mediador e com formação multidisciplinar (observado sua graduação, buscava-se o curso na tabela e o enquadrada nas grandes áreas do conhecimento) (CNPQ, [s.d.]). É de valia comentar que os indivíduos desprezados neste estudo ora não disponham de documentação necessária na Secretaria (histórico escolar e/ou diploma de graduação), ora não finalizaram o curso, sendo assim não contabilizados. Dado o exposto, correlacionou-se os dados com a bibliografia que aporta o artigo.

A partir do primeiro gráfico (Figura 1) pode-se constatar que dentre 1968 a 1977 houve a totalidade 78 (setenta e oito) matriculados e 51 (cinquenta e um) desprezados. Destes 60 (sessenta) pertenciam a Ciências Agrárias, 10 a Sociais Aplicadas e 08 Humanas. Avaliar este primeiro espaço temporal do programa fortalece a ideia inicial defendia por Coelho (2014), a qual reforçava a concepção de ER no país de início pautava-se num desenvolvimento técnico, de projetos e mudança do rural (majoritariamente atribuído a Ciências Agrárias) e não humanístico.

Figura 1 - espaço temporal de 1968 a 1977

"CIÊNCIAS AGRÁRIAS "CIÊNCIAS SOCIAIS APLICADAS =CIÊNCIAS HUMANAS $=D E S P R E Z A D O S$

70

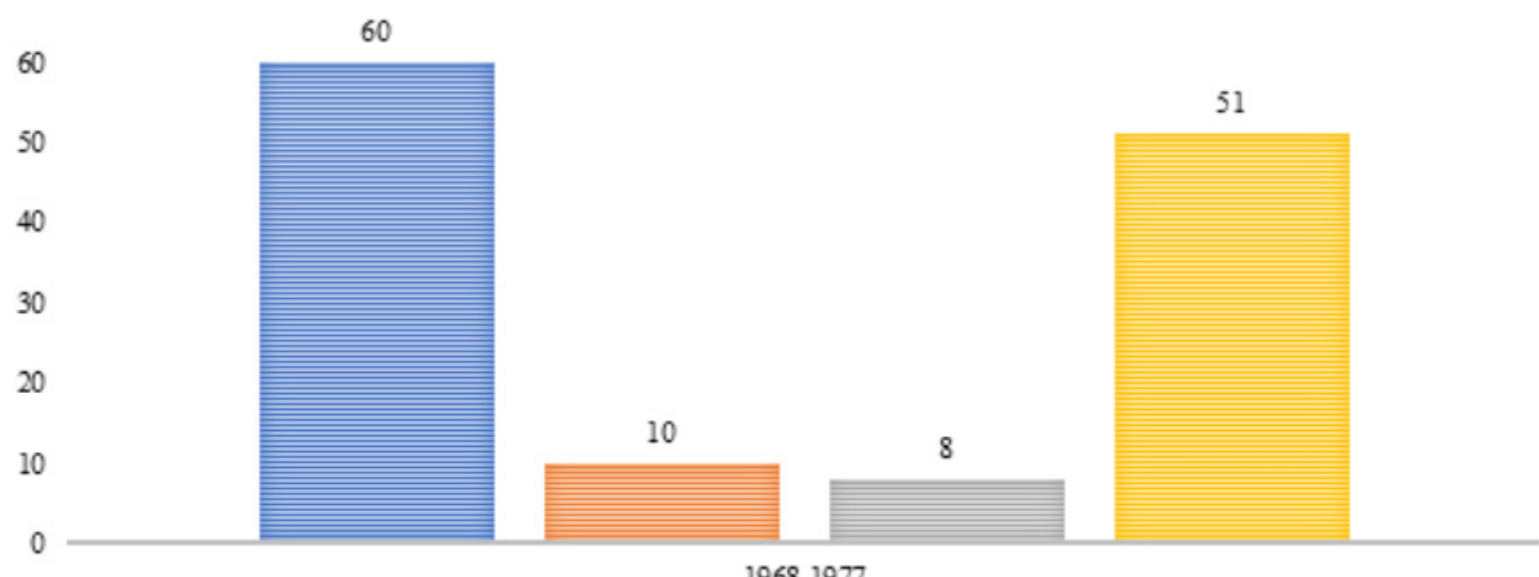

$1968-1977$

FONTE: Desenvolvido pelos Autores a partir do acervo da Secretaria do PPGER (2019). 
Landini (2015), corrobora nesta premissa ao versar que a visão de projeto dada pelos formados nas Ciências Agrárias distancia daqueles com formação nas Sociais Aplicadas e Humanas: o primeiro preocupa-se com a produção técnica e os demais com os processos sociais que envolvem os agricultores. Lusa (2013), versa que os debates da ER iniciam a partir do século XX onde se tinha uma política específica de atenção ao rural com ênfase na prática de acompanhamento da agricultura (ainda que rudimentar), sendo justificada pela política econômica nacional. Este tipo de atividade pautava em, essencialmente, "à transmissão de conhecimentos de uma fonte geradora (exemplo, as universidades) a um receptor, que era o público rural" (LUSA, 2013, p. 117).

É pertinente traçar que neste espaço analisado pode-se notar o modelo de ER difusional, importado dos Estados Unidos a qual, essencialmente, concentrava-se na transferência de tecnologias de especialistas para os produtores (a desvalorização da ciência empírica do produtor e o estabelecimento de relações hierárquicas entre extensionistas e favorecidos são características marcantes deste episódio). De fato, o saber levado ao campo emergia tão-só das academias (e acadêmicos) que por sua vez poucas vezes estiveram no lócus para perceber as necessidades locais (LANDINI, 2015).

O segundo gráfico (Figura 2) aponta que, dentre os anos de 1978 e 1987, houveram 106 (cento e seis) matrículas e 34 (trinta e quatro) desprezados. Dos discentes, 51 (cinquenta e um) eram das Ciências Agrárias; 22 (vinte e dois) das Ciências Aplicadas; 28 das Ciências Humanas; 1 da Linguística, Letras e Artes e 4 pertenciam a Ciências da Saúde. Neste período pode-se verificar a multidisciplinaridade entre as áreas do saber, ainda que as Ciências Agrárias exibissem predominância.

Figura 2 - Espaço temporal de 1978 a 1987
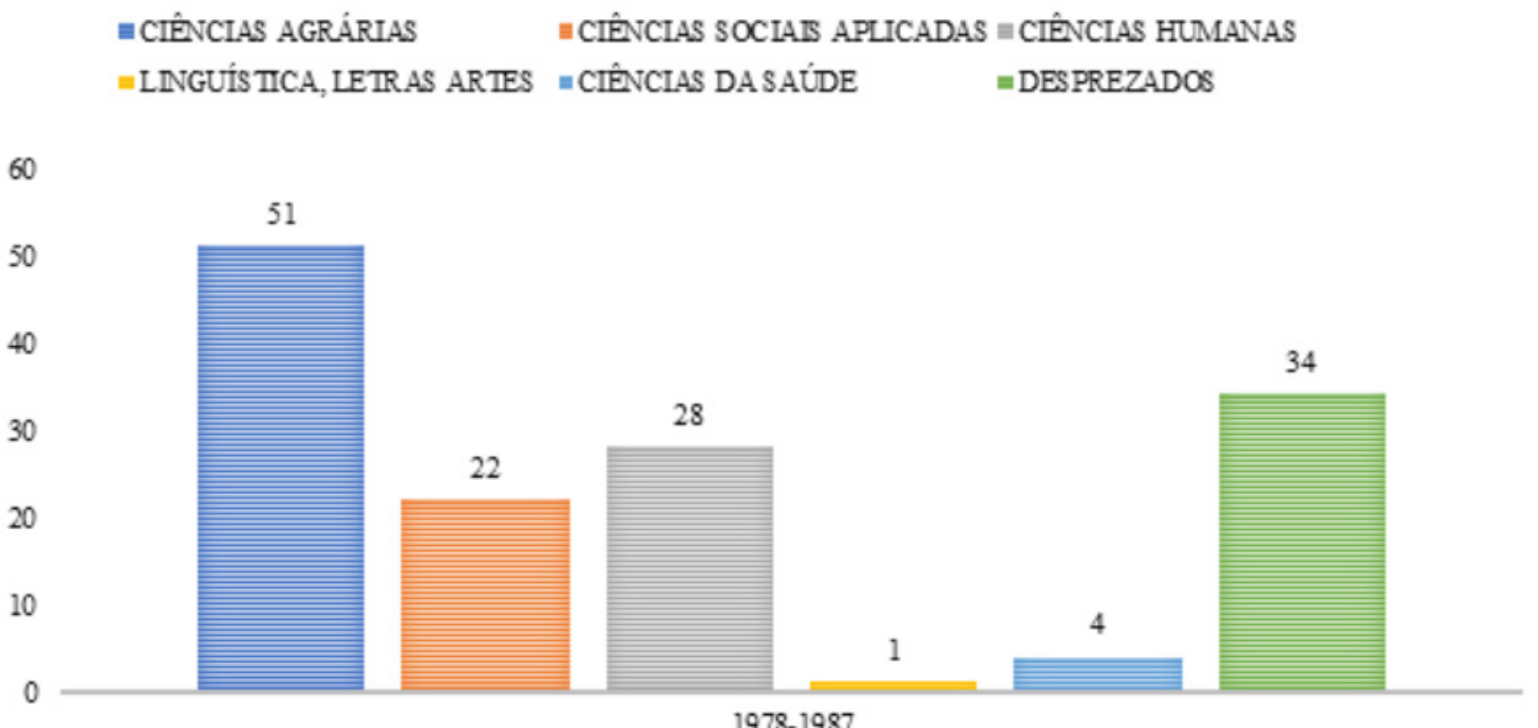

FONTE: Desenvolvido pelos Autores a partir do acervo da Secretaria do PPGER, 2019.

A linha de transmissão de conhecimento e difusão de tecnologia linear, conceituado por Rogers e Shoemaker (1974), ainda predominava no meio acadêmico. Porém, com a defasagem de tecnologia e a oportunidade de os agricultores falarem sobre aquilo que thes era conferido surge a necessidade de se pensar um novo projeto para a extensão, para além do que é técnico. Advindo desta necessidade, a multidisciplinaridade tomou espaço no palco acadêmico rompendo a fronteira de pensamento particularizado de que competia tão-só às Ciências Agrárias tratar das questões do campo e quem nele reside. 
De tal modo, pode-se entender que a ER desassemelhava da Extensão Agrícola ao envolver ' $n$ ' variáveis em seu debate e isto, concomitantemente, geraria a participação do saber acadêmico ao popular (que o ajustará segundo suas necessidades). Equivale dizer, noutros termos, que o conhecimento científico ainda que exiba complexidade não remete necessariamente ao melhor (COELHO, 2014) se o extensionista não fosse capaz de leva-lo ao cidadão rural adequando-o às necessidades locais.

O gráfico da Figura 3 apresenta 104 matriculados e 20 desprezados no período datado de 1988 a 1997. Destes, 36 pertencem a Ciências Agrárias; 31 (trinta e um) a Ciências Sociais Aplicada; 32 (trinta e dois) a Ciências Humanas; 2 (dois) a Linguística, Letras e Artes e 3 (três) das Ciências da Saúde.

Figura 3 - espaço temporal de 1988 a 1997
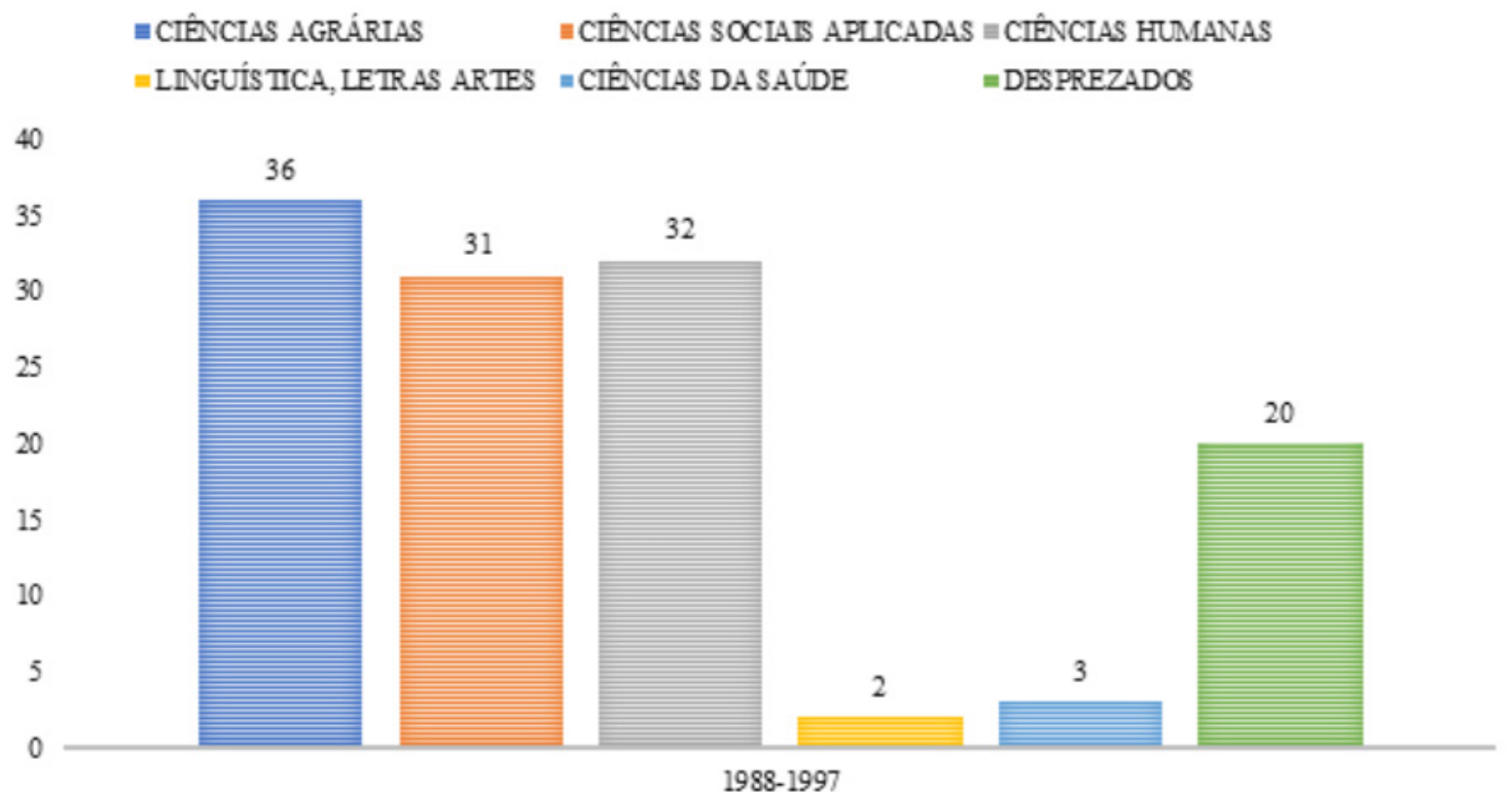

FONTE: Desenvolvido pelos Autores a partir do acervo da Secretaria do PPGER (2019).

Numa projeção teórica-temporal, a ação do agente de extensão estava centrada na simplificação de processos de inovação a partir da articulação entre diferentes atores: produtores, comerciantes, indústria, centros de pesquisa, setor público, entre outros (LANDINI, 2015). Assim, percebe-se que as distintas formações insurgem num período de críticas ao modelo difusional e propõe a horizontalidade entre extensionistas e produtores, visando a construção conjunta de ações e conhecimentos superados, nomeado assim de ER crítica. Vê-se que, aqui, a ação extensionista não assume exclusivamente olhar técnico, mas sobretudo humanístico.

Rodrigues (1997, p. 55) versa que tal orientação se dá pois o extensionista "não é mais um 'agente de mudança' manipulador, é o interlocutor tecnicamente competente de um relacionamento dialógico horizontal, democrático". Com este novo panorama, abriu-se espaço para a pluralidade das áreas na ER as questões que se tornavam recorrentes: entender quem são as pessoas que vivem no campo e suas necessidades (UFV-CCA, 200-) exigindo a inserção de demais profissionais de outras áreas.

Já o gráfico da Figura 4 tem como abordagem os anos de 1998 a 2007. Neste período, totalizou-se 124 (cento e vinte quatro) matriculados e um total de zero desprezados, sendo 31 (trinta e um) pertencente a Ciências Agrárias; 47 (quarenta e sete) a Ciências Sociais Aplicadas; 30 a Ciências Humanas; 10 a Linguística, Letras e Artes; 3 das Ciências da Saúde e 3 da Ciências Biológicas. 
Figura 4 - Espaço temporal de 1998 a 2007

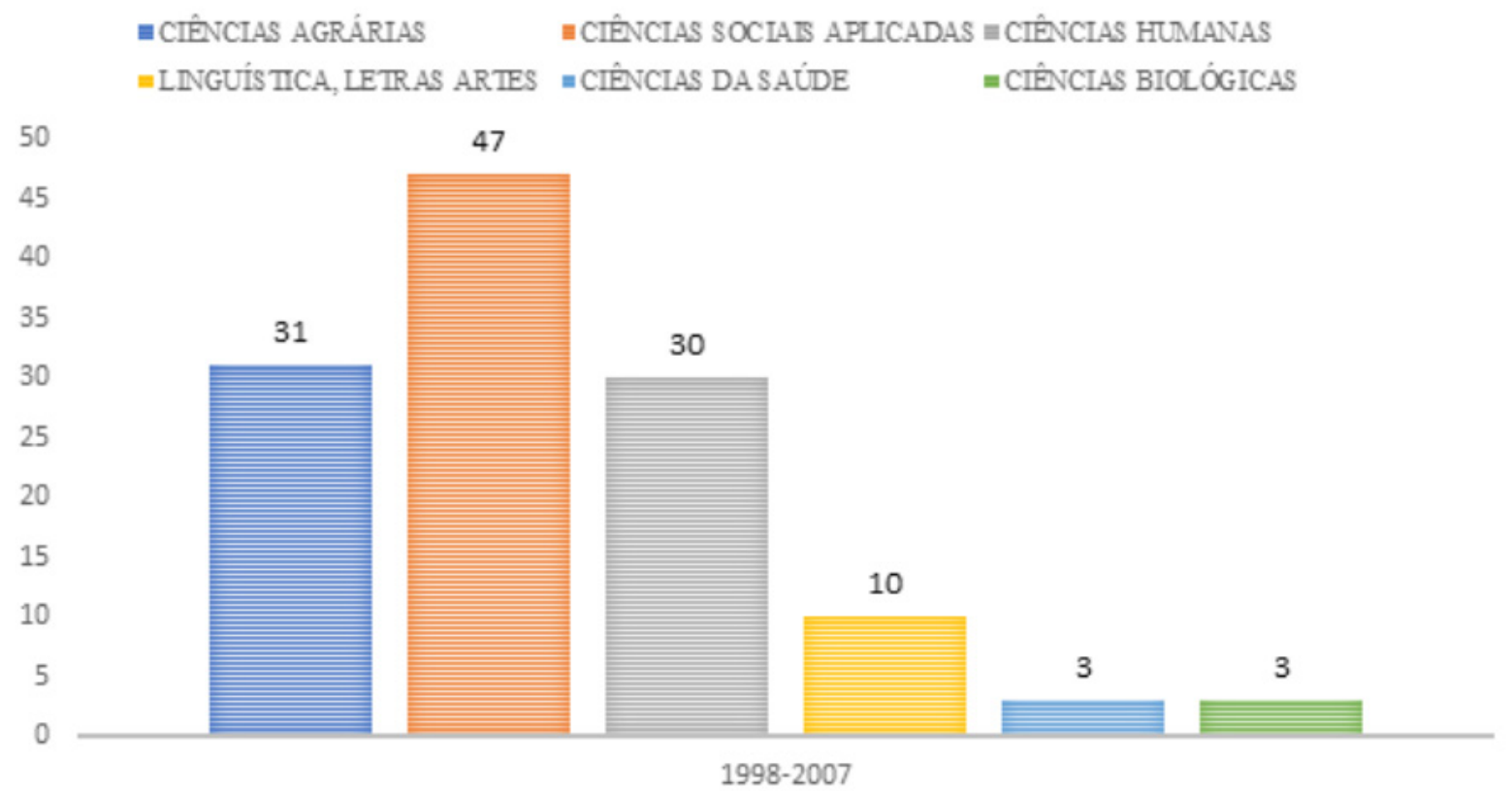

FONTE: Desenvolvido pelos Autores a partir do acervo da Secretaria do PPGER (2019).

Neste panorama Coelho (2014), contribui ao ponderar que há então a diversificação dos saberes das nomeadas Ciências da Natureza e a manipulação de biotecnologias buscaram "romper" os limites naturais de plantio. Nisto, a inserção de profissionais da área tornava-se essencial na ER já que é um conhecimento para além da Agronomia, mas interconectando Fitologia, Fitotecnia, Biologia, Biotecnlogia, dentre outras (ROGERS; SHOEMAKER, 1974; LANDINI, 2015).

Goodman; Sorj; Wilkson (2008), por sua vez, corroboram nesta premissa ao ponderar que com o uso de biotecnologias há um aumento na produção agrícola, não estando assim a mercê de aspectos climáticos ou de pragas na plantação. Entende-se, pois, que o PPGER se direcionava a tal preocupação admitindo profissionais das Ciências Biológicas e da Saúde que focalizam seus esforços nestes estudos.

Finalmente, a Figura 5 datado de 2008 a 2018, exibe uma totalidade de 140 (cento e quarenta) estudantes divididos nas áreas de: Agrárias 50 (cinquenta); Sociais e Aplicadas 28 (vinte e oito); Linguística, Letras e Artes 03 (três); Saúde 03 (três); Biológicas 01 (um); Engenharias 06 (seis) e Exatas e da Terra 03 (três). Aqui, vê-se a multidisciplinaridade que o programa assume ao abarcar oito das nove áreas do conhecimento estabelecidas pelo CNPq ([s.d.]). 
Figura 5 - Espaço temporal 2008 a 2018
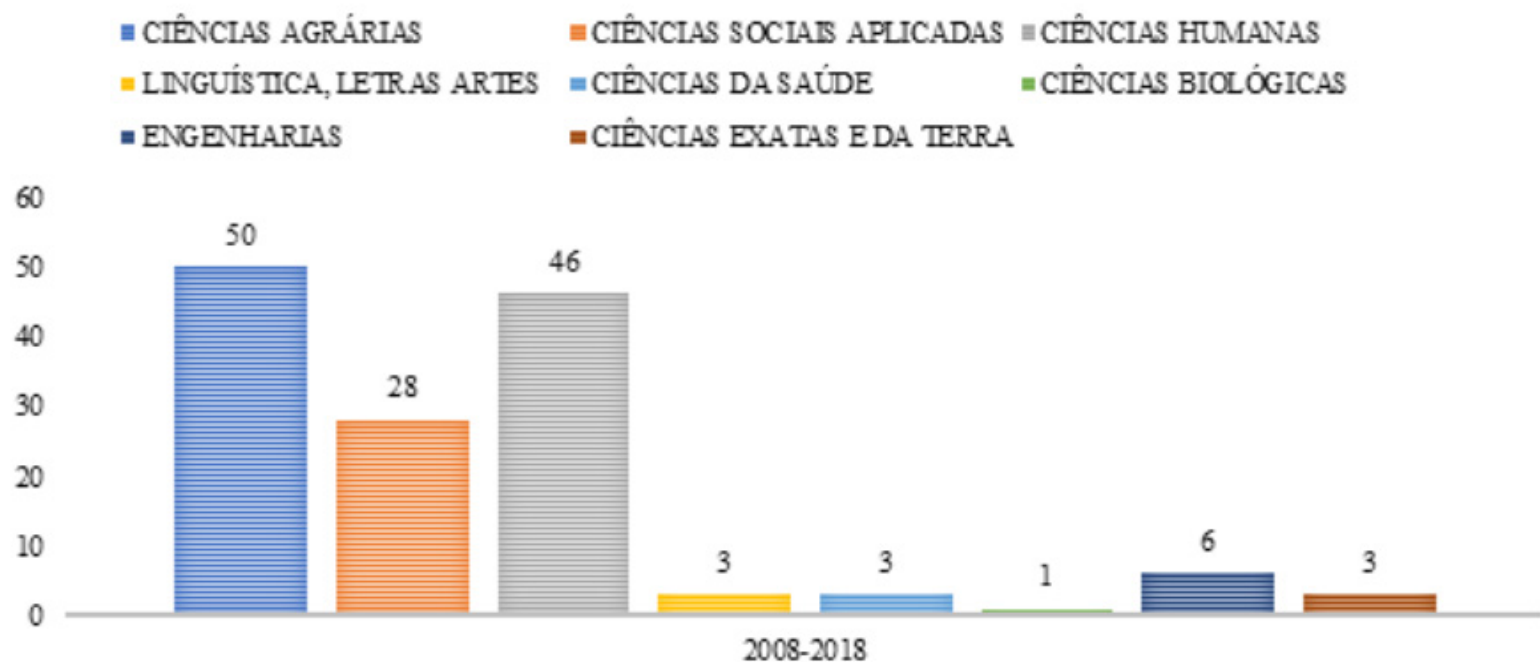

FONTE: Desenvolvido pelos Autores a partir do acervo da Secretaria do PPGER (2019).

Outro tópico exibido por Coelho (2014), e que favorece elucidar neste gráfico (Figura 5), reforça a concepção do extensionista enquanto mediador para o desenvolvimento rural, está no que entende por orientação técnica. Esta, diferente da assistência técnica (pautada na indicação de insumos para obtenção de resultados; cunho industrial; sem preocupação com a sustentabilidade da produção e ação enquanto tão-só difusão e transferência), anseia promover intervenções no local; ofertar mudanças condicionadas por questões políticas e sociais; modifica habilidades manuais e são, sobretudo, participativas. A prática da ER, conforme demonstrado pelo estudo, é vasta e se revela por intervém dos objetos de estudo já definidos. Dias (2018), corrobora nesta perspectiva ao versar que cabe ao extensionista -mediador- expor viés comunicativo (disseminar a informação e inovações); político (perceber os interesses locais e facilitar os processos legislação - público).

Isto, equivale dizer que, a ER passa a ser vista como adaptação dos contextos locais fundamentada na demanda e sobretudo adequar o que se tem por inovações ao local que está. Aspecto representado neste período analisado com a presença de diversos profissionais de áreas distintas. Existe, pois, um redesenho do programa à temática das Ciências Humanas e Sociais Aplicadas para entender as transformações sociais que interseccionam o modus vivendi do rural. Tal fenômeno pode ser notado ao observar que (Figura 6): 
Figura 6 - Percurso temporal do PPGER 1968 - 2018
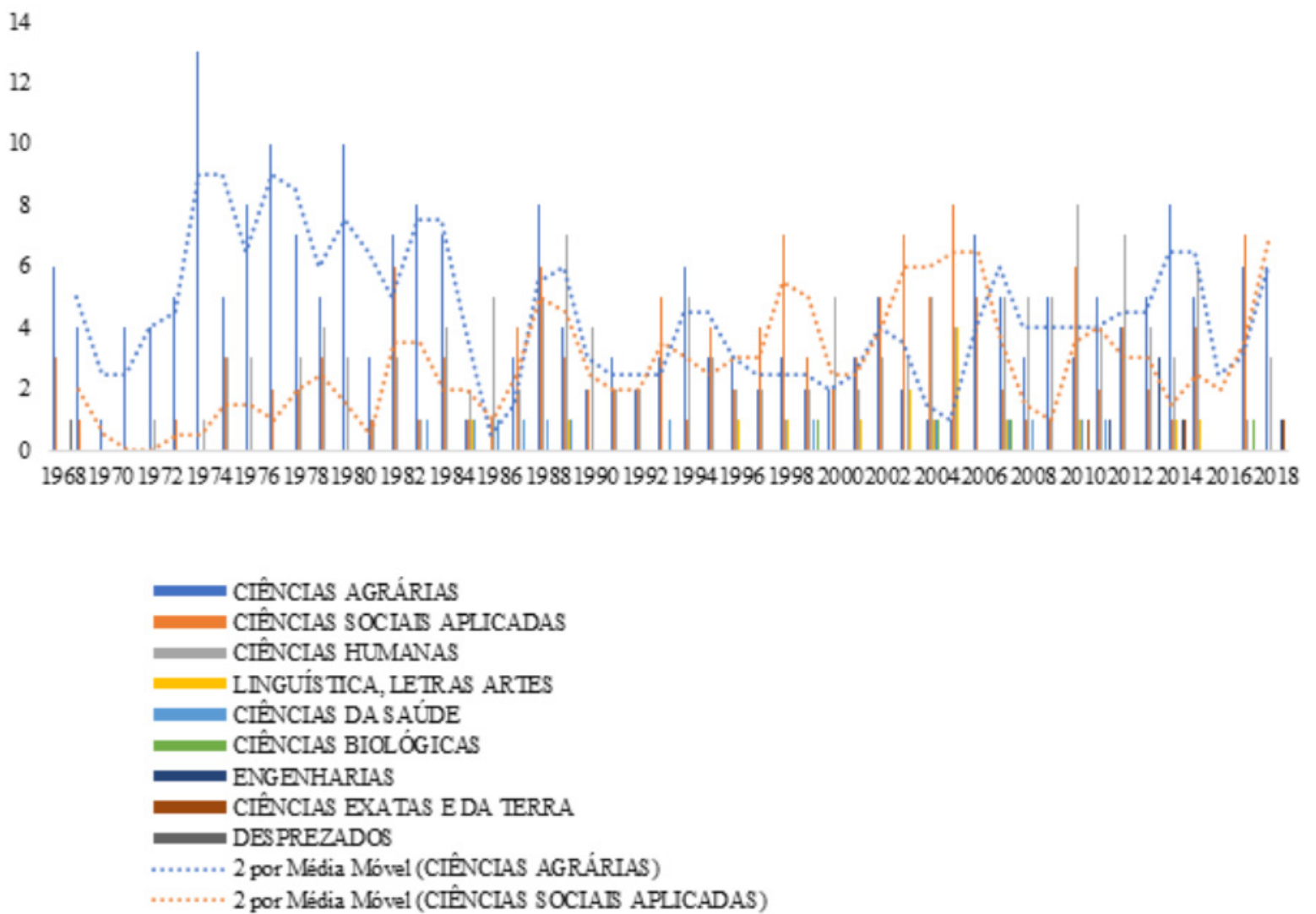

FONTE: Desenvolvido pelos Autores a partir do acervo da Secretaria do PPGER (2019).

Há de se considerar que este índice plural entre as diferentes ciências é reflexo de pesquisas direcionadas as distintas esferas relacionadas ao processo de constituição das identidades socioculturais e das políticas públicas em contextos rurais (PROGRAMA, 2018). Outro ponto de reflexão correlaciona a aproximação das pesquisas para além de tecnicidade ou produção agrícola. Privilegia-se a ação extensionista na temática das redes sociais; dos processos indenitários e representacionais; das práticas comunicativas; dos processos cooperativistas e associativistas, dos componentes entre comunicação, cultura, política e democracia. Questões que afetam a vida rotineira nas complexas sociedades contemporâneas.

Por conseguinte, as alterações de estudos dedicados aos aspectos sociais condicionam a valorização da identidade cultural e social do cidadão rural; do reconhecimento e pertencimento ao espaço onde vivem e convivem; da cidadania que interferem na revisão das suas identidades, sobretudo a profissional, bem como as relações instituídas entre trabalhador e meio ambiente (GEHLEN, 2004). A contribuição do extensionista se fundamenta, assim, na percepção que o rural carece de diversos atores (não só do técnico, mas também humanístico; político; econômico e cultural) dos quais irão oportunizar sua participação nos diversos palcos que lhe faz referência. É emergente a necessidade de análises da agricultura contemporânea e, não menos válido, de suas mudanças sociais.

De tal modo, a participação do agricultor é necessária para fortalecer a mediação do extensionista e Coelho (2014, p. 39) elucida esta temática ao comentar que "esse novo tipo de ciência é aqui denominado ciência (com)partilhada. Inspirada nos estudos etnocientíficos, esse tipo de saber é gerado por experimentações nas quais os agricultores se tornam experimentadores, parceiros e agentes das pesquisas com os pesquisadores". 
Novaes (1978, p. 178) concentra estas premissas ao dissertar que: "[...] Mas, em todas as formas, todos se propõem a ser ponte, estar entre, fazer meio de campo. Fazer mediação é traduzir, e/ou introduzir falas, linguagens...". Apropriando ainda desse autor, um dos fatores que fortalece o extensionista enquanto mediador para a melhoria do lócus em que se faz presente se justifica com a participação das lideranças locais, como elucida:

Enfim, a sugestão é que articular analiticamente as singularidades das trajetórias individuais das lideranças com os processos de construção dos movimentos pode ser útil para rediscutir as questões da mediação interna e externa presentes em suas diretrizes políticas. (NOVAES, 1978, p. 182).

A participação conjunta (extensionista e atores locais) condiciona, de tal maneira, o fortalecimento do local e percepção daquilo que lhe convém -como voz e visibilidade nos palcos que lhe cabe, aqui com recorte no político- (AZEVEDO, 2012). Considerar este cenário também fortalece o debate dado por Freire (1983, p. 76), comentando que "nem os camponeses, nem a ninguém, se persuade ou se submete a força mítica da propaganda quando se tem uma opção libertadora".

Desta forma, quando o extensionista toma para si o papel de mediador em prol do local, nada se faz senão com a intenção de trazer a melhoria daquele grupo, eximindo de qualquer hierarquização onde o saber científico (tido como máximo) sobressai e molda o popular (TODOROV, 1993), o que de fato, as Ciências Agrárias I prioriza em suas análises e o PPGER se orienta promovendo a formação de Mestres e Doutores na área independente de suas formações anteriores, priorizando a interdisciplinaridade teórica e metodológica aplicada a Extensão Rural, o consolidando como um dos programas mais antigos do país com mais de 50 anos de existência.

\section{Considerações finais}

Durante as cinco décadas de existência do PPGER é percebido sua inserção às temáticas sociais ao mesmo tempo que dispõe de uma flexibilidade frente ao que afeta diretamente o rural, objeto de estudo. É possível verificar que as pesquisas desenvolvidas acompanharam as transformações sociais ao longo dos períodos, visto que nas duas primeiras décadas seus trabalhos tinham por mote a prestação de assistência voltada à alimentação, educação, saúde da família e produção de roupas e plantio ao cidadão rural.

As décadas seguintes apontaram para a valorização cultural e simbólica do campo e para a participação política, social e econômica de outros segmentos sociais rurais, tais como a mulher e a juventude, que passaram a ser reconhecidos como atores sociais importantes, demandantes e beneficiários de políticas públicas específicas, e cuja implementação exigiu um reordenamento das instituições atuantes no meio rural. Nesse novo contexto, inserem-se profissionais das diversas áreas do saber que cooperam na busca de romper a fronteira de pensamento particularizada, apontando perspectivas teóricas e metodológicas a entender o rural para além do que é técnico, mas espaço de subjetividade e hibridação.

A promoção do desenvolvimento rural sustentável, da agricultura familiar, da produção agroecológica, da igualdade de gênero, raças e etnias são objetivos centrais da política pública de extensão recente, ressaltando-se que as novas metodologias utilizadas pelo(a)s extensionistas deve priorizar processos dialógicos e participativos de educação e formação das populações rurais. Nesse sentido, pode-se perceber que a produção acadêmica do PPGER tem acompanhado analiticamente as mudanças sociais, políticas, econômicas e culturais, bem como as políticas públicas e arranjos institucionais que promovem tais mudanças e fortalecem sua execução por mais de 50 anos, consolidando-o na área de Agrárias I enquanto programa moldável às demandas que o rural exige.

\section{Referências}

AZEVEDO, V. M. Os desafios para o empoderamento da mulher agricultora a partir do Programa de Aquisição de Alimentos: o caso de Barbacena-MG. Dissertação (Mestrado em Extensão Rural) - Universidade Federal de Viçosa, Viçosa, 2012.

BARDIN, L. Análise de conteúdo. Lisboa: Edições 70, 1977. 
BRASIL. Ministério da Educação. Portaria $\mathrm{N}^{\circ}$ 982, de 26 de julho de 2012. Reconhece os cursos de pós-graduação stricto sensu relacionados no anexo da portaria. Disponível em: 2019. Disponível em: <https://www.prpg.usp.br/images/ Downloads/Legislacao/Portarias_MEC/Port. MEC_982_26.07.12.pdf>. Acesso em 01 jul. 2021.

CONHECIMENTO DO CONSELHO NACIONAL CIENTÍFICO E TECNOLÓGICO - CNPQ. Tabela de Áreas do Conhecimento. [s.d.]. Disponível em: $<$ http://www.lattes.cnpq.br/documents/11871/24930/ TabeladeAreasdoConhecimento.pdf/d192ff6b-3e0a4074-a74d-c280521bd5f7>. Acesso em 01 nov. 2021

COORDENAÇÃO DE APERFEIÇOAMENTO DE PESSOAL DE NÍVEL SUPERIOR - CAPES. Documento da Área: Área 42, Ciências Agrárias I, 2019. Disponível em: <https://www.gov.br/capes/ pt-br/acesso-a-informacao/acoes-e-programas/ avaliacao/sobre-a-avaliacao/areas-avaliacao/sobreas-areas-de-avaliacao/colegio-de-ciencias-da-vida/ ciencias-agrarias/ciencias-agrarias $>$. Acesso em 01 jul. 2020.

COORDENAÇÃO DE APERFEIÇOAMENTO DE PESSOAL DE NÍVEL SUPERIOR - CAPES. Tabela de Áreas de Conhecimento/Avaliação. 2021. Disponível em: <https://www.gov.br/capes/pt-br/ acesso-a-informacao/acoes-e-programas/avaliacao/ instrumentos/documentos-de-apoio-1/tabela-deareas-de-conhecimento-avaliacao $>$. Acesso em 01 jul. 2020.

COELHO, F. M. G. A arte das orientações técnicas no campo. Viçosa: Suprema. 2014.

DIAS, M. M. Diversidade Atual das Concepções e Práticas de Extensão Rural. Academia, 2018. Disponível em: <https://www.academia. edu/37220147/Diversidade_atual_das concep $\% \mathrm{C} 3 \% \mathrm{~A} 7 \% \mathrm{C} 3 \% \mathrm{~B} 5 \mathrm{es}$ e_pro $\% \mathrm{C} 3 \% \mathrm{~A} 1$ ticas da_extens $\%$ C3\%A3o_rural $>$. Acesso em 24 abr. 2021 .

DOULA, S. M.; SOUZA, R. S. de. A pós-graduação em extensão rural no Brasil: perfil, dificuldades e perspectivas. RBPG, Brasília, v.3, n.6, 2006. Disponível em $<$ http://ojs.rbpg.capes.gov.br/index. php/rbpg/article/download/111/105>. Acesso em 09 set. 2021.

FONSECA, M. T. L. Extensão Rural: uma educação para o capital. São Paulo: Loyola, 1985.

FREIRE, P. Extensão Rural ou Comunicação. Rio de Janeiro: Paz e Terra, 1983.
GEHLEN, I. Políticas públicas e desenvolvimento social rural. São Paulo Perspec., São Paulo, v. 18, n. 2, p. 95-103, jun. 2004. Disponível em: $<$ https://doi. org/10.1590/S0102-88392004000200010>. Acesso em 04 abr. 2020.

GIDDENS, A. As consequências da modernidade; tradução de Raul Fiker.- São Paulo: Editora UNESP, 1991.

GOODMAN, D.; SORJ, B.; WILKINSON, J. Da lavoura às biotecnologias: agricultura e indústria no sistema internacional. Biblioteca Virtual de Ciências Humanas. Centro Edelstein de Pesquisas Sociais, 2008. Disponível em: <http://www.precog.com. br/bc-texto/obras/goodman-9788599662298.pdf> Acesso em 04 abr. 2020.

LANDINI, F. Concepción de "extensión rural" de los extensionistas rurales argentinos que trabajan en el sistema público nacional com pequeños produtores. Cuad desarro. rural, Bogotá (Colombia) i2. (75), 2015. Disponível em: <https://doi.org/10.11144/ Javeriana.cdr12-75.cere>. Acesso em 04 abr. 2020.

LUSA, M. G. Política Nacional de Assistência Técnica e Extensão Rural e serviço social: o campo como desafio. Cadernos Ceru, v. 24, 2013.

NOVAES, R. R. A mediação no campo: entre a polissemia e a banalização. In.: MEDEIROS, L., BARBOSA, M. V., FRANCO, M. P. et al. (Orgs.). Assentamentos rurais: uma visão multidisciplinar. São Paulo: UNESP, 1994. p. 177-183.

PROGRAMA de Pós-graduação em Extensão Rural. Regimento Interno. 2018. Disponível em: $<$ http://www.posextensaorural.ufv.br/wp-content/ uploads/2018/02/Regimento-PPGER-Final-2019. pdf>. Acesso em 01 jul. 2020.

RAUPP, F. M.; BEUREN, I. M. Metodologia da pesquisa aplicável às ciências sociais. In : BEUREN, I. M. (Org). Como elaborar trabalhos monográficos em contabilidade. 3.ed. São Paulo: Atlas, 2006.

RODRIGUES, C. M. Conceito de seletividade de políticas públicas e sua aplicação no contexto da política de extensão rural no Brasil. Embrapa. Disponível em: <https:/ainfo.cnptia.embrapa. br/digital/bitstream/item/81227/1/Conceito-deseletividade.pdf $>$. Acesso em 01 jul. 2020.

ROGERS, E. M.; SHOEMAKER, F. F. La comunicacion de innovaciones. México: Herrero Hermanos, 1974. 
SÁ-SILVA, J. R.; ALMEIDA, C. D.; GUINDANI,

J. F. Pesquisa documental: pistas teóricas e metodológicas. Revista Brasileira de História \& Ciências Sociais, n. 1, 2009. Disponível em: $<$ https:// periodicos.furg.br/rbhcs/article/view/10351>. Acesso em 04 abr. 2020.

SOARES, T. C. Características do Turismo de Experiência: Estudos de Caso em Belo Horizonte e Sabará sobre a Inovação e Diversidade na Valorização dos Clientes. Universidade Federal de Minas Gerais, 2009. Monografia (Graduação em Geografia) - Departamento de Geografia, Instituto de Geociências, Universidade Federal de Minas Gerais, Belo Horizonte, 2009.

TODOROV, T. A conquista da América - a questão do outro. São Paulo: Martins Fontes, 1993.

UNIVERSIDADE FEDERAL DE VIÇOSA. Centro de Ciências Agrárias - UFV-CCA. Produção: Paula Tibúrcio Melgaço, Viçosa: Editora s.d., 200-. 